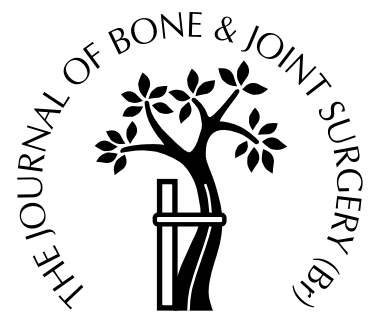

\title{
The role of physiotherapy and clinical predictors of outcome after fracture of the distal radius
}

\author{
A. E. Wakefield, M. M. McQueen \\ From the Lothian University Hospitals NHS Trust, Edinburgh, Scotland
}

$\mathbf{T}$ he capacity for physiotherapy to improve the outcome after fracture of the distal radius is unproven. We carried out a randomised controlled trial on 96 patients, comparing conventional physiotherapy with a regime of home exercises. The function of the upper limb was assessed at the time of removal of the plaster cast and at three and six months after injury. Factors which may predict poor outcome in these patients were sought.

Grip strength and hand function did not significantly differ between the two groups. Flexion and extension of the wrist were the only movements to improve with physiotherapy at six months $(p=0.001)$. Predictors of poor functional outcome were malunion and impaired function before the fracture. These patients presented with pain, decreased rotation of the forearm and low functional scores at six weeks.

Our study has shown that home exercises are adequate rehabilitation after uncomplicated fracture of the distal radius, and routine referral for a course of physiotherapy should be discouraged. The role of physiotherapy in patients at high risk of a poor outcome requires further investigation.

J Bone Joint Surg [Br] 2000;82-B:972-6.

Received 19 July 1999; Accepted after revision 23 March 2000

Fractures of the distal radius account for approximately $14 \%$ of all fractures and are seen most commonly in elderly women. Around 950 people per year sustain this injury in our catchment area, and it often results in permanent disability, particularly in the elderly. ${ }^{1}$

Although physiotherapy is generally regarded as an important part of rehabilitation after fracture of the distal radius, there are few clinical data to support this view. ${ }^{2}$ Patients are either referred routinely to physiotherapy

A. E. Wakefield, MSc, MCSP, Research Physiotherapist M. M. McQueen, MD, Consultant Orthopaedic Surgeon

Orthopaedic Outpatient Department, Lothian University Hospitals NHS

Trust, Lauriston Place, Edinburgh EH3 9YW, UK.

Correspondence should be sent to Ms A. E. Wakefield.

(C)2000 British Editorial Society of Bone and Joint Surgery 0301-620X/00/710377\$2.00 departments, or if they have symptoms which may interfere with recovery. These patients may receive physiotherapy for extended periods of time.

Studies addressing the role of physiotherapy in patients with fractures of the distal radius have shown no functional benefit, although the trials were not randomised, ${ }^{3}$ not blinded and had only a short period of follow-up. ${ }^{4,5}$ The motivation of the patient plays an important part in recovery of function. ${ }^{1}$

The decision to refer a patient to physiotherapy after a fracture is not based on defined criteria, but on the subjective assessment by the orthopaedic surgeon. However, those who would most benefit from this form of therapy have not been identified.

We therefore carried out a randomised controlled trial on patients with fractures of the distal radius immobilised in a plaster cast. Our aim was to compare the functional outcome of patients who received physiotherapy with those receiving instruction in home exercises alone, and to identify early which parameters are indicative of poor functional outcome.

\section{Patients and Methods}

Between May 1997 and March 1998, 96 patients over the age of 55 years with radiological evidence of a fracture of the distal radius treated by variable periods of immobilisation in plaster were entered into the study. There were nine men and 87 women with a mean age of 72 years (55 to 90). Exclusion criteria included a mental test score of less than $8,^{6}$ participation in another clinical trial, bilateral wrist fractures, previous fractures of the unaffected wrist, any surgical treatment to the wrist and clinical signs of reflex sympathetic dystrophy at the time of removal of the plaster cast. ${ }^{7}$

Of the 96 patients, 78 had sustained their fracture by a simple fall, 12 had fallen from a height, one had been involved in a road-traffic accident and five had suffered a direct blow to the wrist or hand. The most common type of fracture was A3.2 (36\%) followed by C2.1 (18\%). The types of fracture were equally distributed in both groups. Table I gives the details of the patients.

Patients were enrolled into the study on the day that their cast was removed. The rationale was explained in accord- 
ance with the principles laid down by our Ethics Committee and informed consent was obtained. Functional assessment was carried out at six weeks (or at cast removal), and at three and six months after the fracture.

Block randomisation was used to allocate patients to treatment groups using a personal computer program (Excel, release 2.2a; Microsoft Corporation, Redmond, Washington). The observer (AW) was blinded as to which treatment group each patient entered; this reduced observer bias at future assessments. The patients were allocated to two groups as follows: group 1 which consisted of 49 patients who were taught and given a standard sheet of home exercises by the physiotherapist in the fracture clinic and referred for a course of physiotherapy at their local health clinic or hospital; and group 2 which had 47 patients who were instructed in home exercises only. At enrolment, clinical details were obtained for each patient and radiological and functional assessments were carried out. The mean age was 72 years for group 1 and 74 years for group 2

Pain. This was evaluated subjectively using a $10 \mathrm{~cm}$ visual analogue scale (VAS). Patients were asked to mark on the scale the degree of pain felt at rest.

Active range of movement (ROM). This was measured at the wrist and distal radio-ulnar joints using a standard fullcircle goniometer. $^{8-10}$ Intraobserver bias was minimised by careful technique and recordings made in triplicate. The mean of these measurements was noted at each assessment. The observer measured flexion and extension, pronation and supination and radial and ulnar deviation; each was described as a percentage of the unaffected side.

Grip strength. This was measured using a JAMAR Delux Hand Dynamometer, Model 0030J4 (Therapeutic Equipment Corporation, Clifton, New Jersey). ${ }^{11-14}$ In accordance with the guidelines for the use of this device, issued by the American Society for Surgery of the Hand, the second grip handle was used for all patients. The mean of three successive readings was taken for each hand and recorded as a percentage of the unaffected side. ${ }^{15,16}$ Each patient was examined at a similar time of the day at each assessment in order to minimise the effects of diurnal variation. The grip strength of the non-dominant hand was adjusted by $10 \%$ for analysis. 11

Functional assessment. We assessed this using a scoring system devised to assess the activities of daily living. ${ }^{17}$ The results were scored according to the degree of difficulty in carrying out these activities and the scores were converted into percentages of the unaffected side for analysis.

Radiological measurements. This was made by the assessor after the initial examination of the patient. Standard anteroposterior and lateral radiographs were taken before and after reduction of the fracture and on removal of the cast. Dorsal angulation, radial shift and radial shortening were measured at these three stages. ${ }^{18,19}$ These radiological features have been shown to be closely related to long-term function. $^{20}$ All measurements were compared with the unaffected side. Fractures were then classified according to

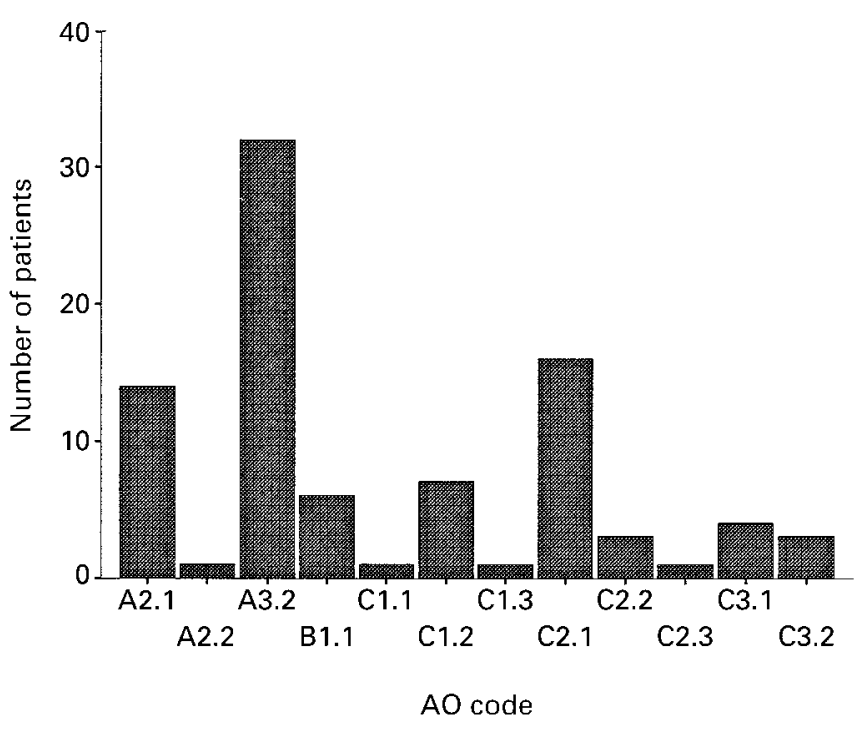

Fig. 1

Distribution of fracture types (AO classification) sustained by the 96 patients.

displacement. Undisplaced or minimally displaced fractures showed $9^{\circ}$ or less of dorsal angulation and $2 \mathrm{~mm}$ or less of radial shortening. Displaced fractures showed dorsal angulation of $10^{\circ}$ or more or $3 \mathrm{~mm}$ or more of radial shortening. The position of the fracture was recorded before reduction and at the completion of immobilisation. The AO system ${ }^{21}$ was used to classify the fractures (Fig. 1).

Quality of life. This was assessed subjectively, in regard to physical and mental health, at the initial assessment and at six months using the UK version of the SF-36 developed by the Medical Outcomes Study in the USA. ${ }^{22}$

Treatment regimes. Home exercises were taught to all patients by the physiotherapist in the fracture clinic following a routine already in general use at our hospital. Patients were encouraged to carry out these exercises three times every day until they were happy with the function of their wrist and hand. Physiotherapy was arranged at each patient's local hospital or clinic, supervised by a qualified state registered physiotherapist. On completion of treatment physiotherapists were asked to record the number, length and types of treatment and any complications experienced by the patients. These records were kept secure until the final analysis. Patients were discharged from physiotherapy at the discretion of the physiotherapist when it was felt that they were no longer improving. Different combinations of active exercises, passive accessory movements and stretches, strengthening and functional exercises were given at each treatment centre. After their six-month assessment comparative analyses were carried out on the two groups.

Statistical analysis. Analysis of covariance (ANCOVA) was used to obtain sufficient power to assess the effect of physiotherapy on outcome at three and six months, using the baseline (six-week) assessment as the covariate. This allowed the comparison of estimated marginal means. Dif- 
Table I. Details of the 96 patients at removal of the cast and at the three-month follow-up

\begin{tabular}{|c|c|c|c|c|}
\hline & \multicolumn{2}{|c|}{ At plaster cast removal } & \multicolumn{2}{|c|}{ At 3-month follow-up } \\
\hline & Group 1 & Group 2 & Completed & Withdrew \\
\hline Number of patients & 49 & 47 & 90 & $\begin{array}{l}2 \text { (group 1) } \\
4 \text { (group } 2)\end{array}$ \\
\hline Mean age in years $( \pm \mathrm{SD})$ & $72 \pm 9.8$ & $74 \pm 9.1$ & $73 \pm 9.4$ & $73 \pm 10.6$ \\
\hline $\begin{array}{l}\text { Gender } \\
\text { Male } \\
\text { Female }\end{array}$ & $\begin{array}{r}5 \\
44\end{array}$ & $\begin{array}{r}4 \\
43\end{array}$ & $\begin{array}{l}9 \\
8.1\end{array}$ & $\begin{array}{l}0 \\
6\end{array}$ \\
\hline Dominant hand injured $(\%)$ & $17(35)$ & $16(34)$ & $30(33)$ & $3(50)$ \\
\hline $\begin{array}{l}\text { Number of displaced fractures }(\%) \\
\text { Before immobilisation } \\
\text { After immobilisation }\end{array}$ & $\begin{array}{l}18(37) \\
17(35)\end{array}$ & $\begin{array}{l}22(47) \\
18(38)\end{array}$ & $\begin{array}{l}39(43) \\
33(37)\end{array}$ & $\begin{array}{l}1(17) \\
2(33)\end{array}$ \\
\hline Mean duration of immobilisation in days ( \pm SD) & $37.0 \pm 6.0$ & $37.0 \pm 6.0$ & $37.0 \pm 5.7$ & $38.0 \pm 6.8$ \\
\hline Number with pre-existing joint disease & 18 & 25 & 41 & 2 \\
\hline Number who received steroids & 2 & 3 & 4 & 1 \\
\hline Number with history of neoplasm & 3 & 3 & 5 & 1 \\
\hline Number who had sustained previous fractures (within 10 years) & 11 & 14 & 23 & 2 \\
\hline
\end{tabular}

Table II. The estimated marginal means ( \pm SEM) for both groups at three and six months as percentage of the uninjured hand

\begin{tabular}{|c|c|c|c|c|}
\hline & Group 1 & Group 2 & $\begin{array}{l}\text { Mean difference } \\
(\mathbf{9 5 \%} \text { CI) }\end{array}$ & p value \\
\hline \multicolumn{5}{|c|}{ JAMAR grip strength } \\
\hline 3 mths & $41.6 \pm 4.3$ & $40.7 \pm 4.6$ & $0.9(-11.8$ to 13.5$)$ & 0.899 \\
\hline $6 \mathrm{mths}$ & $68.5 \pm 6.1$ & $67.3 \pm 6.3$ & $1.2(-16.4$ to 19.0$)$ & 0.885 \\
\hline \multicolumn{5}{|c|}{ Pronation/supination } \\
\hline 3 mths & $92.7 \pm 1.0$ & $93.2 \pm 1.0$ & $-0.5(-3.4$ to 2.4$)$ & 0.731 \\
\hline $6 \mathrm{mths}$ & $96.5 \pm 0.8$ & $95.6 \pm 0.8$ & $0.9(-1.4$ to 3.2$)$ & 0.437 \\
\hline \multicolumn{5}{|c|}{ Flexion/extension } \\
\hline $3 \mathrm{mths}$ & $82.9 \pm 1.8$ & $80.0 \pm 1.9$ & $2.9(-2.3$ to 8.0$)$ & 0.269 \\
\hline 6 mths & $96.6 \pm 2.4$ & $84.4 \pm 2.5$ & $12.2(5.4$ to 19.2$)$ & $0.001 *$ \\
\hline \multicolumn{5}{|c|}{ Radial and ulnar deviation } \\
\hline 3 mths & $85.1 \pm 2.4$ & $81.8 \pm 2.5$ & $3.3(-3.6$ to 10.2$)$ & 0.889 \\
\hline $6 \mathrm{mths}$ & $94.2 \pm 2.9$ & $91.0 \pm 3.0$ & $3.2(-4.7$ to 12.0$)$ & 0.391 \\
\hline \multicolumn{5}{|c|}{ Functional scores } \\
\hline $3 \mathrm{mths}$ & $88.3 \pm 1.4$ & $87.6 \pm 1.5$ & $0.7(-3.4$ to 4.7$)$ & 0.766 \\
\hline $6 \mathrm{mths}$ & $94.5 \pm 1.5$ & $94.2 \pm 1.5$ & $0.3(-4.0$ to 4.6$)$ & 0.437 \\
\hline
\end{tabular}

* significant

Table III. Raw means ( \pm SD) for pain scores at six weeks and at three and six months

\begin{tabular}{llll}
\hline Pain & Group 1 & Group 2 & $\begin{array}{l}\text { Mean difference } \\
\text { (95\% CI) }\end{array}$ \\
\hline 6 weeks & $2.3 \pm 2.2$ & $2.0 \pm 2.1$ & $0.3(-0.5$ to 1.2$)$ \\
3 months & $1.4 \pm 1.6$ & $1.4 \pm 1.7$ & $0(-0.7$ to 0.7$)$ \\
6 months & $0.9 \pm 1.6$ & $0.8 \pm 1.4$ & $0.1(-0.7$ to 0.8$)$ \\
\hline
\end{tabular}

ferences between the estimated marginal means and 95\% confidence intervals were calculated for each time period (SPSS 8.0 for Windows; SPSS, Chicago, Illinois).

An outcome score for each parameter, weighted by the standard deviation of the measurements, was calculated for each patient. This score combined the range of flexion, extension, pronation, supination and radial and ulnar deviation with the patient's JAMAR grip and functional outcome score. Totals were added together to give each individual a total outcome score (TOS) at three and six months. At six months this continuous score ranged from -6.5 (the worst outcome) to 4.7 (the best outcome).

Forward stepwise regression was carried out using the TOS (SPSS 8.0 for Windows). This demonstrated the association between outcome and potential predictors of outcome. A pilot study was performed to calculate the minimum sample size needed to obtain $90 \%$ power to detect a difference between the two groups at the 5\% level. A difference of 2.5 units or $22 \%$ of the combined TOS, was considered to be clinically relevant. To demonstrate this difference 22 patients were needed in each study group. Since the trial was pragmatic in design, patients were analysed by intention to treat.

\section{Results}

Six patients withdrew from the study before the threemonth stage, two from group 1 and four from group 2 . Preliminary analysis indicated that sufficient numbers of patients had been recruited and therefore only 66 were followed up at six months (group 1, 34; group 2, 32). Comparisons of withdrawals before the three-month assessment are shown in Table I. The median number of physiotherapy treatments was three (1 to 22 ).

All measurements of outcome examined such as pain, flexion/extension, radio-ulnar deviation, pronation/supination, JAMAR grip strength and functional scores, improved significantly over the time period. When the outcomes were compared between the two groups using ANCOVA (Table II) and Mann-Whitney U tests (Table III), only flexion/ extension at 26 weeks was significantly better in group 1 $(\mathrm{p}=0.001)$ (Fig. 2).

Figure 3 shows the distribution of the TOS data. Indicators of poor outcome at three and six months were malunion of the fracture, decreased functional scores and limited rotation at the six-week assessment. The clinical 


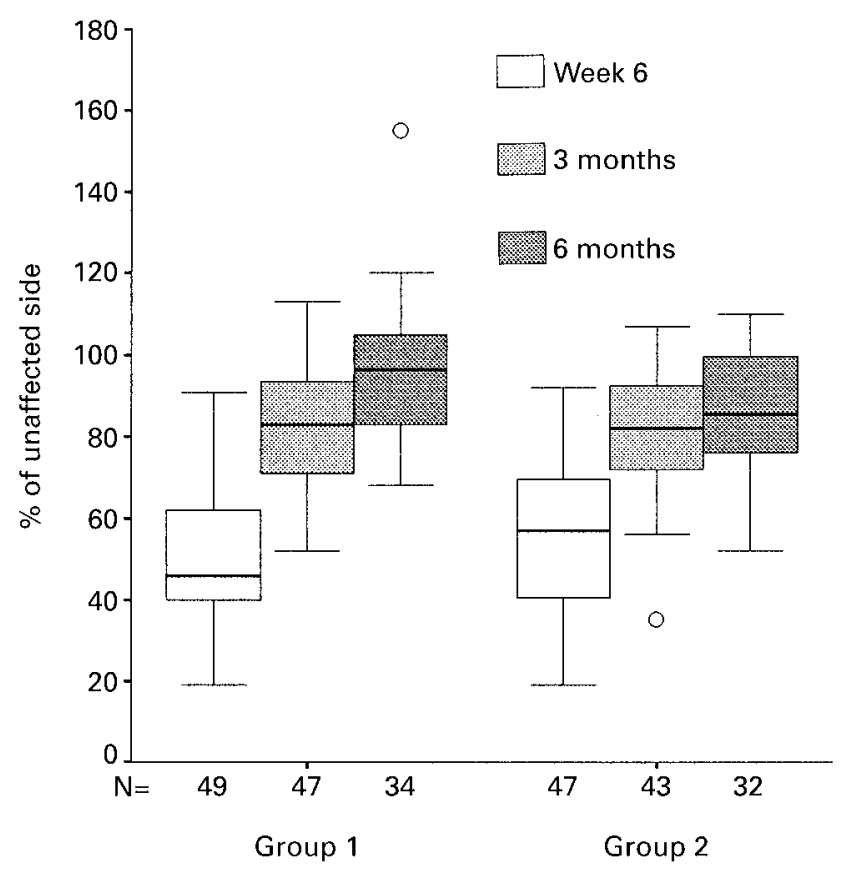

Fig. 2

Boxplot for flexion/extension showing distribution of data around percentiles at each time period for both groups.

parameters which contributed to the TOS were then removed from the model (i.e. ROM, JAMAR and functional score). Poor outcome was predicted by malunion, a high level of pain at six weeks, the severity of the initial displacement of the fracture and limitation of wrist and hand function before injury.

Data on 50 patients were analysed for quality of life (SF36 questionnaire). All domains of health improved significantly over the six-month time period, particularly the 'role physical' and 'bodily pain'. There were, however, no significant differences in any of the measured parameters between the two groups when compared, using ANCOVA. Informal investigation of the 'at risk patients' identified by the multivariate analysis was then undertaken in order to formulate new hypotheses for future studies.

Significant displacement was observed in 40 patients and malunion was seen in 35 at six weeks. Between the groups, comparisons using ANCOVA showed that the physiotherapy group had significantly better flexion/extension at six months $(p=0.044)$. There were no significant differences for the other parameters measured. Patients with a score less than the mean value of pronation/supination at the six-week assessment ( $83 \%$ of the unaffected side) were identified. The mean TOS of the two groups were compared using Student's $t$-tests at the three- and six-month reviews. There were no significant differences between the two groups. Our study was too small to examine the effect of the type of fracture (AO classification) on outcome. All statistical tests carried out were non-significant and the type of fracture did not act as a predictor in the multivariate analysis.

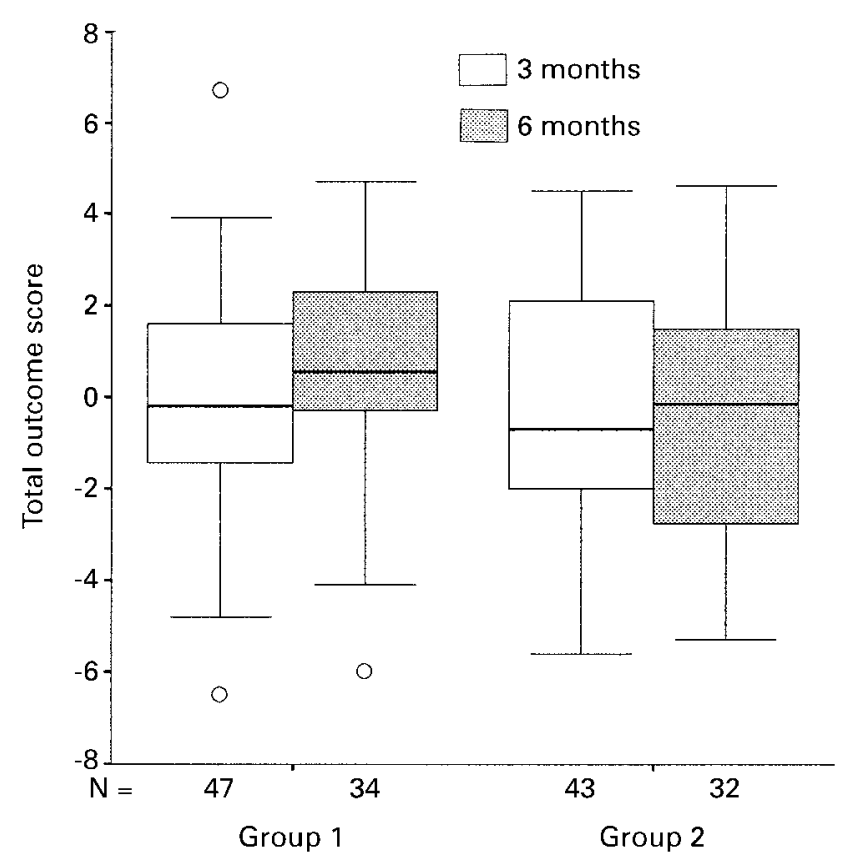

Fig. 3

Distribution of data for TOS for both groups at three and six months.

\section{Discussion}

The treatment of patients presented in our study is standard in most orthopaedic outpatient departments. ${ }^{23}$ Most of the fractures $(93 \%)$ seen were divided between AO types A (53\%) and $C(40 \%)$, the most common type of fracture being the A3.2 (extra-articular with metaphyseal comminution). Our pilot study indicated that age was most strongly linked with poor outcome and that the older woman, of limited physical ability and poor bone stock, appeared to be particularly at risk. The results of the larger study show that although all patients improved over time in terms of functional outcome including ROM and grip strength, only flexion and extension improved significantly with physiotherapy. This was confirmed both by ANCOVA and by direct comparative statistics of the two groups. There is no significant correlation between flexion and extension and the patients' functional scores. Therefore we can presume that it is not a clinically relevant measurement of function. Quality of life was measured using the SF-36 questionnaire before and after physiotherapy. As there was no significant difference in SF-36 scores between the two groups at six months, we can also presume that a course of physiotherapy did not directly influence the wellbeing of this group of patients.

The course of physiotherapy had no proven effect on the rate or quality of recovery after an uncomplicated fracture of the distal radius. This supports earlier studies ${ }^{3-5}$ which showed that home exercises given by a physiotherapist soon after the period of immobilisation, are equally effective in restoring function. Many patients are currently being 
referred unnecessarily for physiotherapy, expending valuable time and effort by both the physiotherapist and patient.

In order to identify the group of patients at risk of poor outcome, multivariate analysis showed that a patient over 55 years of age presenting with malunion at six weeks after a displaced fracture, with a history of functional impairment before the injury, is at high risk of poor outcome. A high level of pain, reduced rotation of the forearm and a reluctance to use the wrist and hand for functional activities also carry a poor prognosis.

It was impossible formally to evaluate the effect of physiotherapy in these 'at-risk' patients because of the small size of the subgroups; until proven otherwise a course of physiotherapy should still be offered to these patients.

In order to make useful comparisons between groups, all the modalities examined were standardised by expressing the degree of dysfunction as a percentage of the uninjured contralateral limb. This minimises the variation within groups, which may often be considerably affected by a single individual and, in addition, gives a measure of return to normality for any one patient since each patient acts as his own control. ANCOVA was used in the direct comparison of the two groups since this method takes into account the widespread variation in baseline measurements between patients, as well as examining improvement in performance.

The authors would like to thank the physiotherapists working in Orthopaedic Outpatients and in the other hospitals and clinics involved in this study. We would also like to thank Dr R. Prescott at the Medical Statistics Unit, University of Edinburgh, for his statistical advice and guidance during the pilot study.

No benefits in any form have been received or will be received from a commercial party related directly or indirectly to the subject of this article.

\section{References}

1. Bacorn RW, Kurtzke JF. Colles' fracture: a study of two thousand cases from the New York State Workmen's Compensation Board. J Bone Joint Surg [Am] 1953;35-A:643-58.

2. Golden GN. Treatment and prognosis of Colles' fracture. Lancet $1963 ; 1: 511-5$

3. Oskarsson GV, Hjall A, Aaser P. Physiotherapy: an overestimated factor in after treatment of fractures in the distal radius? Arch Orthop Trauma Surg 1997;116:373-5.

4. Pasila M, Karaharju EO, Lepisto PV. Role of physical therapy in recovery of function after Colles' fracture. Arch Phys Med Rehabil $1974 ; 55: 130-4$
5. Gronlund B, Harreby MS, Kofoed R, Rasmussen L. The importance of early exercise therapy in the treatment of Colles' fracture: a clinically controlled study. Ugeskr Laeger 1990;152:2491-3.

6. Folstein MF, Folstein SE, McHugh PR. 'Mini-mental state': a practical method for grading the cognitive state of patients for the clinician. J Psychiatr Res 1975;12:189-98.

7. Veldman PH, Reynen HM, Arntz IE, Goris RJ. Signs and symptoms of reflex sympathetic dystrophy: prospective study of 829 patients. Lancet 1993;342:1012-6.

8. Rothstein JM, Miller PJ, Roettger RF. Goniometric reliability in a clinical setting: elbow and knee measurements. Phys Ther 1983;63:1611-5.

9. Fish DR, Wingate L. Sources of goniometric error at the elbow. Phys Ther 1985;65:1666-70.

10. Gajdosik RL, Bohannon RW. Clinical measurement of range of motion: review of goniometry emphasising reliability and validity. Phys Ther 1987;67:1867-72.

11. Bechtol CO. Grip test: the use of a dynamometer with adjustable handle spacings. J Bone Joint Surg [Am] 1954;36-A:820-4.

12. Fess EE. A method for checking Jamar dynamometer calibration. $J$ Hand Ther 1987;1:28-32.

13. Kirkpatrick JE. Evaluation of grip loss: a factor of permanent disability in California: summation and conclusions of the subcommittee for study of grasping power of the committee on industrial health and rehabilitation of the California Medical Association. California Medicine 1956;85:314-20

14. Kirkpatrick JE. Evaluation of grip loss: a factor of permanent partial disability in California. Ind Med Surg 1957;26:285-9.

15. American Society for Surgery of the Hand. Clinical assessment recommendations. The hand: examination and diagnosis. 2nd edition. New York: Churchill Livingstone, 1983:106-7.

16. Fess EE. Documentation: essential elements of an upper extremity assessment battery. In: Hunter JM, Schneider LH, Mackin EJ, Callahan $\mathrm{AD}$, eds. Rehabilitation of the hand: surgery and therapy. St Louis, etc: CV Mosby, 1990:53-80.

17. Sheehan NJ, Sheldon JF, Marks D. Grip strength and torquometry in the assessment of hand function in patients with rheumatoid arthritis. Br J Rheumatol 1983;22:158-64.

18. Van der Linden W, Ericson R. Colles' fracture: how should its displacement be measured and how should it be immobilized? J Bone Joint Surg [Am] 1981;63-A:1285-8.

19. Melone CP Jr. Open treatment for displaced articular fractures of the distal radius. Clin Orthop 1986;202:103-11.

20. Villar RN, Marsh D, Rushton N, Greatorex RA. Three years after Colles' fracture: a prospective review. J Bone Joint Surg $[\mathrm{Br}]$ 1987;69-B:635-8

21. Müller ME, Nazarian S, Koch $\mathbf{P}$, Schatzker J. The comprehensive classification of fractures of long bones. Berlin, etc; Springer-Verlag, 1990.

22. Ware JE, Snow K, Konsinski M, Gandek B. SF-36 Health Survey manual and interpretation guide. The Health Institute, New England Medical Centre, 1993:3-19.

23. McQueen MM. Epidemiology of fractures of the radius and ulna. In: McQueen MM, Jupiter JB, eds. Radius and ulna. Oxford: Butterworth-Heinemann, 1999:5-11. 